\title{
The New European Biodiversity Strategy: A Challenge to the Restoration Community!
}

Kris Decleer

I ast year the European Union (EU) adopted a new strategy to "halt the loss of biodiversity and the degradation of ecosystem services in the EU by 2020 and restore them in so far as feasible." The strategy is built around 6 measurable targets with a comprehensive set of actions that focus on the main drivers of biodiversity loss.

The cornerstone of the existing EU nature legislation is formed by the Birds and Habitats Directives. In response to these Directives, the $27 \mathrm{EU}$ member states already designated core areas for approximately 2000 rare and threatened species and habitat types deemed to be of EU importance in view of their vulnerability. This resulted in the largest coordinated network of protected areas in the world, consisting of more than 26,000 terrestrial and marine sites covering $751,150 \mathrm{~km}^{2}$ of terrestrial habitat (17.5\% of Europe) and $199,000 \mathrm{~km}^{2}$ of marine habitat. The Directives require that the protected habitats and species are maintained or restored to a "favorable conservation status" across their natural range within the EU (i.e. are thriving and in a healthy condition). According to the recent results of the obligatory monitoring of their conservation status, only $17 \%$ of the habitat types and species protected under the Habitats Directive are in a favorable conservation status at the EU-biogeographical level, the majority being in an "unfavorable-inadequate" or "unfavorable-bad" state. For the European bird species protected under the Birds Directive, only 52\% are deemed to be in a secure condition at present (EEA 2010). The first target of the new Biodiversity Strategy aims at 34\% of the habitats and $26 \%$ of the species in a favorable or significantly improved conservation status by 2020 and $80 \%$ of the protected bird species populations secured. In the forthcoming years, the EU member states will therefore have to invest in the implementation of adequate conservation and restoration measures within the designated network of protected areas, amounting to an estimated total cost of $€ 6$ billion a year.

A second principal target of the EU 2020 Biodiversity Strategy focuses on maintaining and enhancing ecosystem

Ecological Restoration Vol. 30, No. 2, 2012

ISSN 1522-4740 E-ISSN 1543-4079

C 2012 by the Board of Regents of the University of Wisconsin System. services, and restoring at least $15 \%$ of degraded ecosystems across the EU. Many of Europe's ecosystems are heavily degraded which drastically reduces their ability to deliver essential goods and services to society. Moreover, $30 \%$ of Europe is moderately to highly fragmented due to changing land uses and increased urbanization and infrastructure developments (EEA 2011). By 2014 the EU member states have to develop a strategic framework to set priorities for ecosystem restoration at the subnational, national, and EU level. Another action is the elaboration of an EU-wide Green Infrastructure Strategy by the end of 2012 to promote reconnection of fragmented natural areas, improve the delivery of ecosystem goods and services (e.g., protection against floods and erosion, clean water supply, pollination), and tackle the adverse effects of climate change. Mapping and assessment of ecosystems and their services will be necessary throughout the EU, while the monetary value of ecosystem services needs to be better integrated into national and EU accounting and reporting systems. By 2014 a European methodology will be developed for assessing the impact of EU funded projects, plans, and programs on biodiversity. The ultimate goal is a sustainable, more "biodiversity proof" policy at all levels. Furthermore, a European initiative will be launched by 2015 to ensure there is "no net loss" of ecosystems and their services (e.g., through compensation or offsetting schemes).

Farming and forestry concern almost $72 \%$ of the land use in Europe and play an important role in Europe's biodiversity. Unfortunately, today only $15-25 \%$ of Europe's once extensive high nature value farming (e.g., different types of semi-natural grassland) remain, and most species that depend on traditional agricultural practices are in decline, while no more than $1-3 \%$ of Europe's forests are still in an entirely natural and unmanaged state. A third target of the new EU biodiversity strategy, therefore, focuses on an increased contribution of agriculture and forestry in the maintenance and restoration of biodiversity and ecosystem services. Among the many actions under this target, we mention the implementation of sustainable forest management plans for all public and large private forests by 2020. The EU Common Agricultural Policy, currently accounting for $€ 55$ billion euro, or $40 \%$ of the EU budget, will be reformed to increase the maintenance and 
enhancement of biodiversity and ecosystem services, with one of the currently heavily debated policy proposals being the implementation of $7 \%$ of agricultural land (equivalent to about $129,000 \mathrm{~km}^{2}$ EU-wide) as an Ecological Focus Area. It remains uncertain where these focus areas will be located, which quality objectives need to be met, and how they will be managed, all aspects of great ecological relevance in this ongoing debate.

The fourth target of the 2020 EU-Biodiversity strategy includes the restoration of marine ecosystems in support of achieving Good Environmental Status by 2020 and the maintenance or restoration of fish stocks to levels that can produce a maximum sustainable yield for fisheries by 2015. The fifth target aims at the restoration of ecosystems degraded by invasive alien species by better control and eradication of a selection of priority species by 2020 . The sixth and last target defines actions to help averting global biodiversity loss and reducing adverse effects of EU policies with respect to biodiversity outside Europe.

The European Biodiversity Strategy is a milestone for the biodiversity strategy of the EU and its 27 member states. The European Commission and its political leaders are to be applauded for their holistic and integrated vision and their role on the global scene as strong biodiversity advocators in the Conference of Parties to the Convention on Biological Diversity. The targets and actions they enforce themselves are very ambitious, especially in view of the difficult economic times and nearby time-limit. Achieving the EU 2020 targets will require the full engagement and commitment of a wide variety of stakeholders and deserves as much support as possible from all European scientists, practitioners and policy makers active in the field of conservation and ecological restoration.

The challenges are huge. Consistent, legal enforcement of the targeted actions in all EU member states is recommended, but for political reasons not evident in practice. More than ever we have to call for sufficient financial resources or redistribution of existing resources to enable implementation of the new strategy. Probably also more private resources have to be allocated, a mechanism that is still much less established in the EU compared to the U.S. A science-based approach of all restoration works is essential if the investment of resources is to be successful. This implies involvement of scientists or the use of scientific knowledge and site-specific research in the design, execution, and follow-up of each restoration project. More demonstration projects must be promoted and best practice experience shared. Ecologists must be more involved in spatial planning and land use management, and the design of green infrastructure or agricultural focus areas in order to maximize cost-efficiency and aim for a climate change-proof approach. Reinforcement of dialogue and cooperation between scientists and stakeholders, involvement of the wider public, and biodiversity education and awareness are critical for success. Finally, there is certainly room for more practically-oriented research on themes such as (De Meester et al. 2011): resilience and dynamics of ecosystems and species (meta-)populations; climate change adaptation and mitigation; interaction between abiotic conditions, fragmentation, species assemblages, ecosystem functioning and ecosystem services; economic consequences of biodiversity loss, long-term monitoring, biodiversity outside protected areas, eco-evolutionary dynamics-just to name a few themes.

Business as usual will not be enough. Dear colleagues, we have work to do!

\section{References}

Biodiversity Information System for Europe (BISE). biodiversity. europe.eu.

De Meester L., P. van Tienderen, M. Werger and A. Hector. 2011. Challenges for biodiversity research in Europe. Procedia Social and Behavioral Sciences 13:83-100.

European Commission. 1992. The Natura 2000 Network. ec.europa.eu/environment/nature/natura2000/index_en.htm.

European Commission. 2011. The EU Biodiversity Strategy to 2020. ec.europa.eu/environment/nature/biodiversity/ comm2006/2020.htm

European Commission. 2012. Green Infrastructure. ec.europa .eu/environment/nature/ecosystems/index_en.htm.

European Environmental Agency. 2010. EU 2010 Biodiversity Baseline. Technical report No 12/2010.

European Environmental Agency. 2011. Landscape fragmentation in Europe. EEA Report No 2/2011.

Kris Decleer

European representative in the Board of Directors of SER International Board Member SER Europe Research Institute for Nature and Forest, Kliniekstraat 25, 1070 Brussels, Belgium 